\title{
New Coordination Modes for Modified Schiff Base Ti(IV) Complexes and Their Control Over Lactone Ring-Opening Polymerization Activity
}

\author{
Christopher B. Durr ${ }^{\dagger}$, and Charlotte K. Williams* ${ }^{*} \dagger$ \\ ${ }^{\dagger}$ Chemistry Research Laboratory, Department of Chemistry, University of Oxford, 12 Mansfield Road, \\ Oxford, OX13TA, United Kingdom. Corresponding author email: Charlotte.williams@chem.ox.ac.uk
}

\begin{abstract}
A series of 8 new bis(alkoxy)bis(phenoxy-imine)titanium(IV) catalysts, coordinated by Schiff base ligands derived from o-vanillin (2-hydroxy-3-methoxybenzaldehyde), show good activity and control for the ring-opening polymerization (ROP) of $\varepsilon$-caprolactone or $\omega$-pentadecalactone. The new complexes are easily prepared in two high-yield steps from commercial reagents. The new ligands can all adopt two different coordination modes, depending on the steric bulk on the imine: a 6-membered $\mathrm{N}-\mathrm{O}$ chelate and/or a 5-membered $\mathrm{O}-\mathrm{O}$ chelate. The complexes show three different structures, depending on the ligand coordination mode: Type A (N-O:N-O); Type B (N-O:O-O); and Type C (O-O:O-O). in all cases, the structures are confirmed, in solution, using variable temperature NMR spectroscopy and, in the solid state, using X-ray crystallography. The complex structure influences the polymerization rate, with the catalytic activities decreasing in the order: Type C > Type B > Type A for both monomers. Overall, the work demonstrates potential to use these new ligands to access particular coordination modes which allows enhancement of catalytic activity.
\end{abstract}

\section{Introduction}

Metal complexes of Schiff base ligands are important for many different catalytic transformations, including epoxidation, hydrolysis, polymerization and cross-coupling reactions. ${ }^{1-5}$ Catalysts featuring bidentate phenoxy-imine ligands are straightforward to synthesize and already offer a multitude of sites for structure-activity exploration. ${ }^{6-13}$ Here, bis(Schiff base)Ti(IV) catalysts are developed for lactone ring opening polymerization (ROP). ${ }^{14}$ The process is a controlled polymerization applicable to the production of various polyesters; some of which are degradable and may be alternatives to polyolefins. The polymerization is critically dependent on the catalyst applied, not only in terms of activity but also for good control and selectivity. In this field, titanium(IV) catalysts have previously shown high activity, selectivity and control. ${ }^{15-19}$ Additionally, titanium is earth-abundant and has a strong precedent for successful deployment in industrial polymerization catalysis. For example, bis(phenoxy-imine) Group IV complexes are successful and highly active olefin polymerization catalysts; their development was pioneered by Fujita and co-workers working at Mitsui. ${ }^{20}$ Structure activity studies, revealed that some of the best rates are observed for cumyl substituents at the ortho-phenolate site ${ }^{10}$ whilst living polymerization of 
ethene or propene was observed for pentafluorophenyl imine substituents. ${ }^{21-23}$ Bis(phenoxyether) Ti(IV) complexes are also effective olefin polymerization catalysts, although activities are generally lower than phenoxy-imine counterparts. ${ }^{24-25}$ A detailed study of the coordination chemistry of bis(phenoxy-imines)Ti(IV) complexes, reported by Johnson, Davidson and coworkers, showed four different coordination types depending on the steric hindrance of the imine substituent (Scheme 1). ${ }^{26}$ As its size increased, for example with a 2,6- $\mathrm{Pr}_{2}\left(\mathrm{C}_{6} \mathrm{H}_{3}\right)$ substituent, electronically disfavored modes were proposed to form as a means to relieve steric hindrance. At the limit, with a $\left(2,4,6-{ }^{\mathrm{H}} \mathrm{Bu}_{3}\left(\mathrm{C}_{6} \mathrm{H}_{2}\right)\right.$ substituent), dimeric complexes formed featuring a single monodentate phenoxide ligand without any of the target mononuclear complex, even using forcing reaction conditions.

Although there have been many studies of bis(phenoxy-imine) Group IV complexes, there are not yet any analogous investigations using ligands derived from $o$-vanillin. The $o$-vanillin derivatives are attractive as they feature an additional ortho-methoxy substituent, adjacent to the phenolate, and as such offer different coordination modes: either $\mathrm{N}-\mathrm{O}$ or $\mathrm{O}-\mathrm{O}$ chelates should be accessible. There is precedent for complexes of o-vanillin derivatives of the well-known salen ligands (tetradentate Schiff base ligands) and these complexes show both chelate types. ${ }^{27-30}$ For example, these o-vanillin salen ligand formed dinuclear complexes with one metal coordinated by two $\mathrm{N}-\mathrm{O}$ chelates and the other by two O-O chelates. ${ }^{27}$ The different coordination modes also enable access to heterodinuclear complexes which showed promising activity in organo-catalysis and/or magnetic properties. ${ }^{28-30}$ In contrast to the results for tetradentate ligands, here bidentate o-vanillin derived bis(phenoxy-imine) ligands form discrete mononuclear Ti(IV) complexes but show three different coordination types (Scheme 1, A-C).
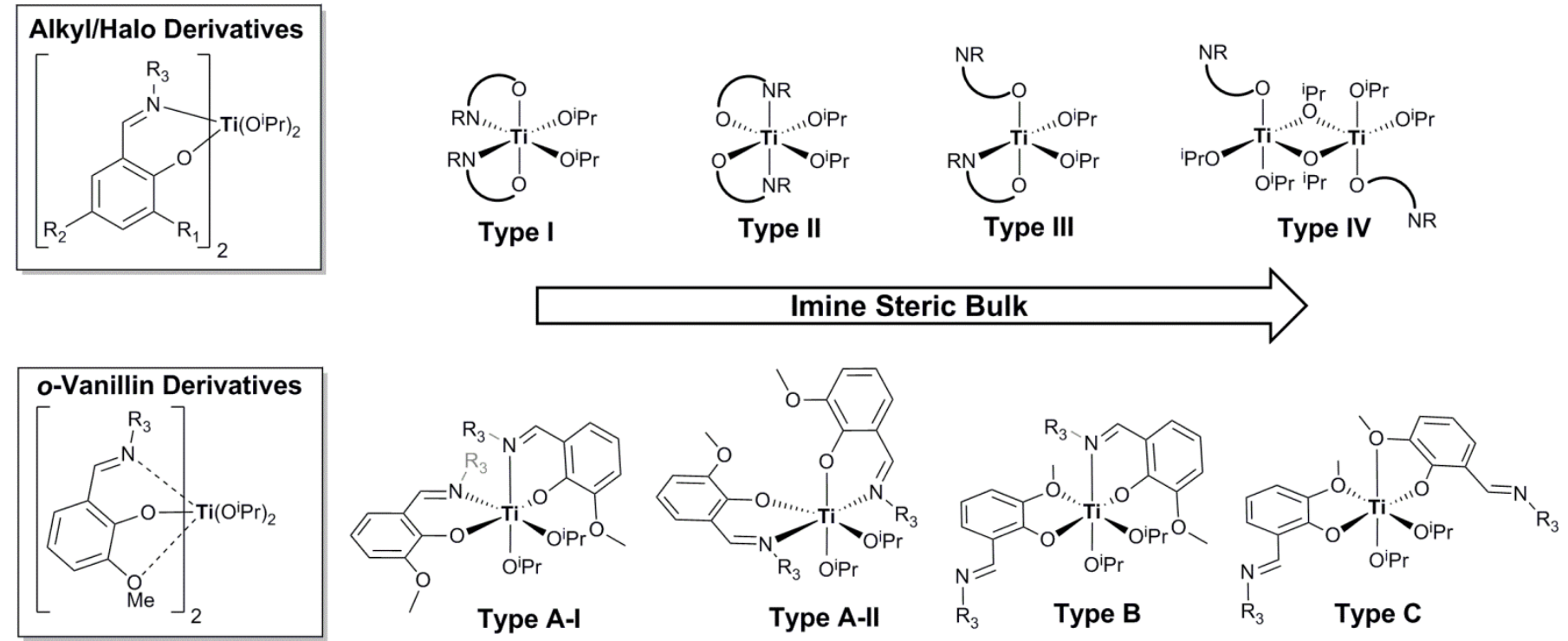

Scheme 1. Summary of the coordination types observed for bis(phenoxy-imine)Ti(IV) complexes, where $\mathrm{R}_{1}=\mathrm{R}_{2}=\mathrm{H}, \mathrm{R}_{3}=$ Aryl, Alkyl (top), ${ }^{26}$ compared with those observed in this work for o-vanillin derived ligands (bottom). 


\section{Results and Discussion}

\section{Complex Synthesis}

The $\mathrm{o}$-vanillin derived Schiff base ligands, $\mathrm{HL}_{\mathbf{1}}-\mathrm{HL}_{\mathbf{8}}$, were synthesized via a one-pot reaction between $O$-vanillin and the desired primary amine, in refluxing acidified ethanol (see ESI for experimental details and Figs. $\mathrm{S} 1-8$ for the ${ }^{1} \mathrm{H}$ NMR spectra). The amines were selected to enable understanding of the influence of steric hindrance of the imine substituents over the resulting coordination chemistry. The crude products were purified through either crystallization from ethanol or by washing with pentane (see ESI for further details). Yields, after purification, were generally excellent; the final products were soluble in chloroform, THF and, with the exception of $\mathrm{HL}_{8}$, toluene. The $\mathrm{Ti}(\mathrm{IV})$ complexes were prepared by the reaction of two equivalents of $\mathbf{H L}_{1-8}$ with an equivalent of $\mathrm{Ti}\left(\mathrm{O}^{\mathrm{i}} \mathrm{Pr}\right) 4$; the reaction was conducted in dry toluene, at low temperature $\left(-30^{\circ} \mathrm{C}\right.$ to room temperature) and over $18-24 \mathrm{~h}$ (Scheme 2). After removal of the solvents, the complexes $\left[\left(\mathbf{L}_{1-8}\right)_{2} \mathrm{Ti}\left(\mathrm{O}^{\mathrm{i}} \mathrm{Pr}\right)_{2}\right]$ were isolated, as yellow or orange powders, in fair to excellent yields (38\% - 99\%). All the complexes were crystallized either from concentrated THF solutions, at $-30{ }^{\circ} \mathrm{C}$, or by layering hexanes over concentrated $\mathrm{THF}$ or $\mathrm{CHCl}_{3}$ solutions. All the complexes, $\left[\left(\mathbf{L}_{1-8}\right)_{2} \mathrm{Ti}\left(\mathrm{O}^{\prime} \mathrm{Pr}\right)_{2}\right]$, are soluble in chloroform, THF, $\varepsilon$-caprolactone, and toluene, but only sparingly soluble in alkanes, such as pentane and hexanes.

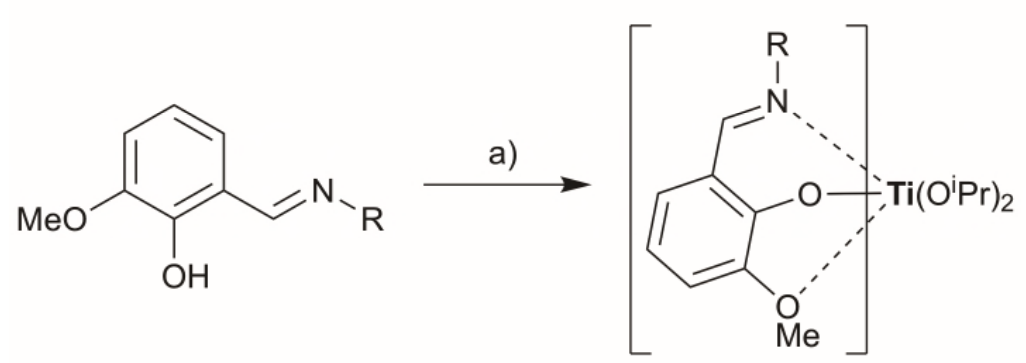

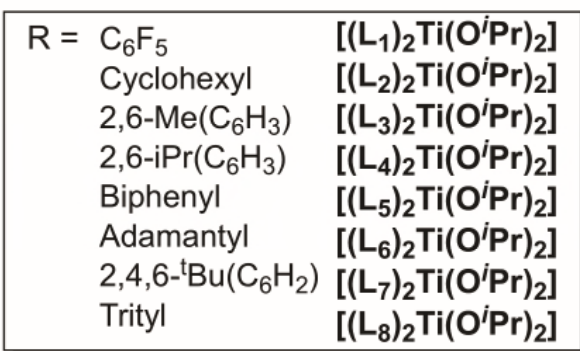

Scheme 2. The synthesis of new Ti(IV) complexes, where dotted bonds indicate the two coordination modes, depending on steric hindrance at R. Reagents and conditions: a) $\mathrm{Ti}\left(\mathrm{O}^{\mathrm{i}} \mathrm{Pr}\right)_{4}$, toluene, $-30{ }^{\circ} \mathrm{C}$ to r.t., $24 \mathrm{~h}$.

The new complexes, [( $\left.\left.\mathrm{L}_{1-8}\right) \mathrm{Ti}\left(\mathrm{O}^{\mathrm{i} P r}\right)_{2}\right]$, were unambiguously characterized by ${ }^{1} \mathrm{H}$ and ${ }^{13} \mathrm{C}\left\{{ }^{1} \mathrm{H}\right\} \mathrm{NMR}$ spectroscopy (Figs.S9-24), MALDI-ToF MS, elemental analysis, and single crystal X-ray diffraction. These new complexes feature different and independent coordination modes: either 6membered $\mathrm{N}-\mathrm{O}$ coordination, and/or 5-membered $\mathrm{O}-\mathrm{O}$ coordination. Thus the complexes feature three different coordination modes: Type A with N-O:N-O coordination, Type B with N-O:O-O coordination and Type C with O-O:O-O coordination (Scheme 1). For any single Type, there are also additional isomers that are theoretically possible, although the eight catalysts synthesized in this series exhibit only four distinct structures (in both solid and solution states), with Type A showing two different isomers. All the new complexes were characterized in the solid state by single crystal $X$-ray diffraction experiments and representative structures are illustrated in Fig. 1.

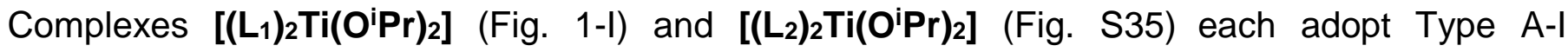
coordination, where the imine nitrogen atoms are located at positions cis to one another. Both 
complexes have imine substituents with rather low steric hindrance $\left(\mathrm{L}_{1}=\mathrm{C}_{6} \mathrm{~F}_{5}\right.$ and $\mathrm{L}_{2}=$ cyclohexyl) and adopt the lowest energy coordination mode common to many other bis(phenoxyimine)Ti(IV) complexes. ${ }^{26}$ In the solid state structure of $\left[\left(\mathrm{L}_{1}\right) \mathrm{Ti}\left(\mathrm{O}^{\mathrm{i}} \mathrm{Pr}\right)_{2}\right]$ this mode may be further enhanced by $\pi$-stacking interactions between one set of the electron deficient $\mathrm{C}_{6} \mathrm{~F}_{5}$ and the adjacent phenyl ring. The average aromatic ring separation is $3.58 \AA$, which is within range of those typically found in the Cambridge Structural Database ${ }^{31}$ (CSD) for $\pi-\pi$ stacking between similar rings (Figure S34).

I)

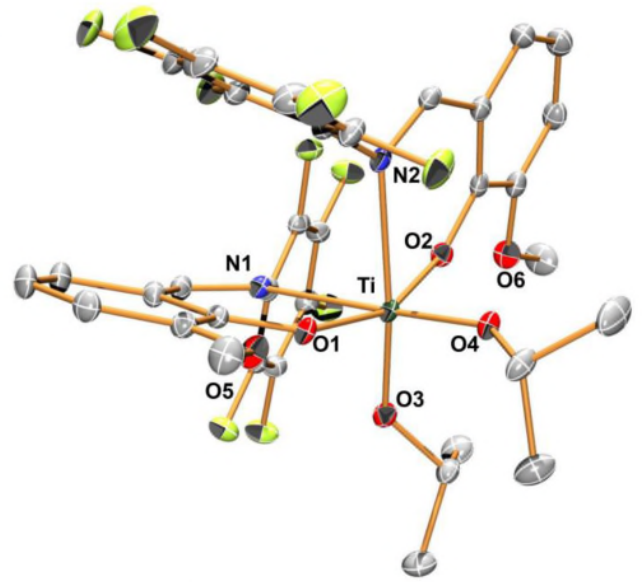

[( $\left.\left.\mathrm{L}_{1}\right)_{2} \mathrm{Ti}\left(\mathrm{O}^{\mathrm{P} P r}\right)_{2}\right]$

Type A-I

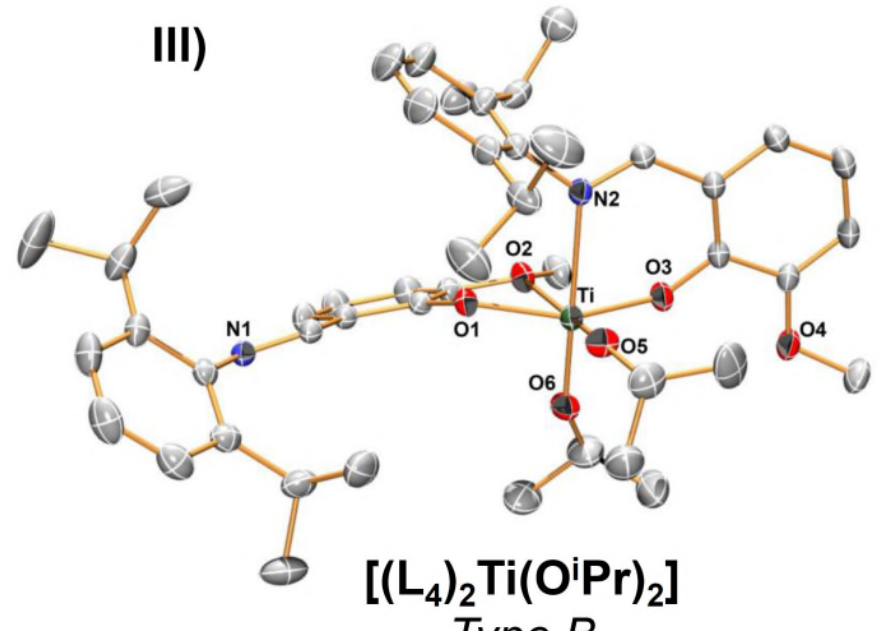

II)

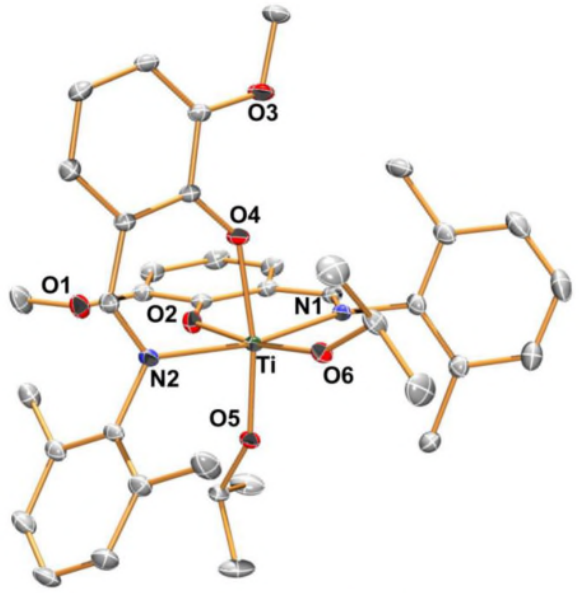

$\left[\left(\mathrm{L}_{3}\right)_{2} \mathrm{Ti}\left(\mathrm{O}^{\mathrm{i}} \mathrm{Pr}\right)_{2}\right]$

Type A-II

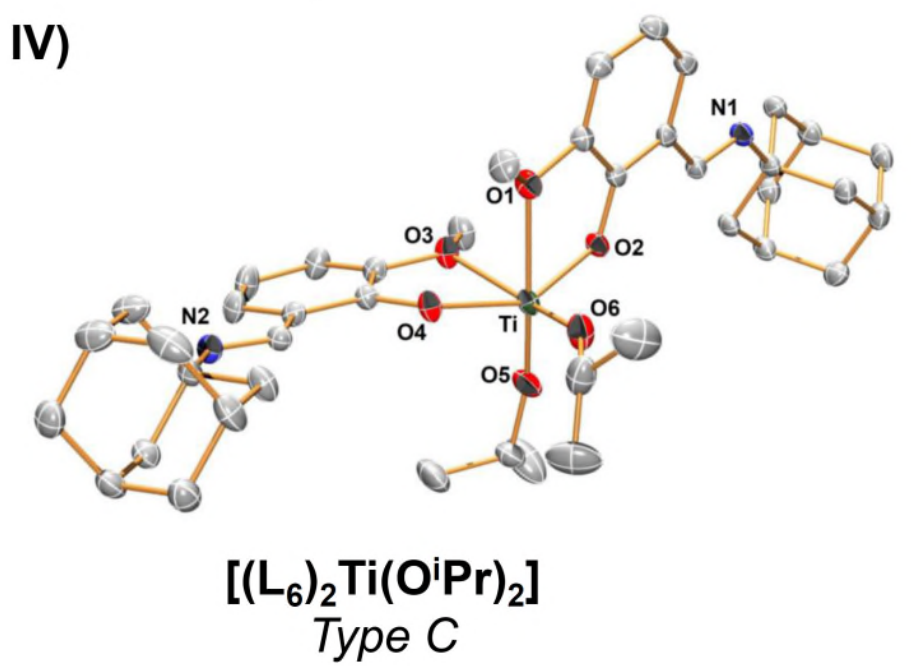

Figure 1. ORTEP representations of the structures of complexes $\left[\left(\mathrm{L}_{1}\right)_{2} \mathrm{Ti}\left(\mathrm{O}^{\mathrm{i}} \mathrm{Pr}\right)_{2}\right](\mathrm{I}),\left[\left(\mathrm{L}_{3}\right)_{2} \mathrm{Ti}\left(\mathrm{O}^{\prime} \mathrm{Pr}\right)_{2}\right](\mathrm{II})$, $\left[\left(\mathrm{L}_{4}\right)_{2} \mathrm{Ti}\left(\mathrm{O}^{\prime} \mathrm{Pr}\right)_{2}\right](\mathrm{III})$, and $\left[\left(\mathrm{L}_{6}\right)_{2} \mathrm{Ti}\left(\mathrm{O}^{\prime} \mathrm{Pr}\right)_{2}\right](\mathrm{IV})$. Ellipsoids drawn at $50 \%$ probability, hydrogen atoms and disorder are omitted for clarity. Green $=$ Titanium, Blue $=$ Nitrogen, Red $=$ Oxygen, Grey $=$ Carbon, Lime $=$ Fluorine.

$\left[\left(\mathrm{L}_{3}\right)_{2} \mathrm{Ti}\left(\mathrm{O}^{\prime} \mathrm{Pr}\right)_{2}\right]$ (Fig. $\left.1-\mathrm{II}\right)$ adopts a different coordination mode, Type A-II, where the imine nitrogen atoms are disposed in a mutually trans geometry. This coordination type also correlates with that seen previously for bis(phenoxy-imine)Ti(IV) complexes, featuring imine substituents of intermediate steric hindrance. Since the coordination geometry is not electronically favored it is 
presumably adopted to minimize steric interactions whilst still maintaining the $\mathrm{N}-\mathrm{O}: \mathrm{N}-\mathrm{O}$ chelates. In this Type $\mathrm{A}-\mathrm{Il}$ mode both the $\mathrm{Ti}-\mathrm{N}$ bond distances are shorter, and the $\mathrm{Ti}-\mathrm{O}$ distances longer, compared to equivalent bonds in Type A-I. Complexes $\left[\left(\mathrm{L}_{4}\right)_{2} \mathrm{Ti}\left(\mathrm{O}^{\mathrm{O}} \mathrm{Pr}\right)_{2}\right]$ (Fig. 1-III) and [( $\left.\left.\mathrm{L}_{5}\right)_{2} \mathrm{Ti}(\mathrm{O} \mathrm{Pr})_{2}\right]$ (Fig. S36) both adopt Type B coordination, with one nitrogen located trans to an $\mathrm{O} P r$ ligand and the other ligand featuring $\mathrm{O}-\mathrm{O}$ coordination with the nitrogen atom not coordinating to Ti. Due to the formation of a five-membered ring, the $\mathrm{O}(1)-\mathrm{Ti}-\mathrm{O}(2)$ angle is more acute, at $72.92(8)^{\circ}$, than the $\mathrm{O}(3)-\mathrm{Ti}-\mathrm{N}(2)$ angle, at $80.72(9)^{\circ}$, with the latter value being similar to that seen in $\left[\left(\mathrm{L}_{2}\right)_{2} \mathrm{Ti}\left(\mathrm{O}^{\mathrm{i}} \mathrm{Pr}\right)_{2}\right]$. Additionally, both $\mathrm{Ti}-\mathrm{O}^{\mathrm{i}} \mathrm{Pr}$ distances are slightly shorter than in Type $A$, with the difference in bond lengths being $\sim 0.05 \AA$, and the unbound imine bond is $0.02 \AA$ shorter than for coordinated analogues.

Complexes [( $\left.\left.\mathrm{L}_{6}\right)_{2} \mathrm{Ti}\left(\mathrm{O}^{\mathrm{P}} \mathrm{Pr}\right)_{2}\right],\left[\left(\mathrm{L}_{7}\right)_{2} \mathrm{Ti}\left(\mathrm{O}^{\mathrm{i}} \mathrm{Pr}\right)_{2}\right]$, and $\left[\left(\mathrm{L}_{8}\right)_{2} \mathrm{Ti}\left(\mathrm{O}^{\mathrm{i}} \mathrm{Pr}\right)_{2}\right]$ all adopt Type $\mathrm{C}$ coordination, where both ligands show O-O chelation (Figs. 1-IV, S37, S38, respectively). [( $\left.\left.\mathrm{L}_{6}\right)_{2} \mathrm{Ti}^{\mathrm{i}}\left(\mathrm{O}^{\mathrm{i}} \mathrm{Pr}\right)_{2}\right]$ has bond angles of: $[\mathrm{O}(1)-\mathrm{Ti}-\mathrm{O}(2)]=73.67(5)^{\circ}$ and $[\mathrm{O}(3)-\mathrm{Ti}-\mathrm{O}(4)]=73.99(5)^{\circ}$; both values are similar to those found in $\left[\left(\mathrm{L}_{4}\right)_{2} \mathrm{Ti}\left(\mathrm{O}^{\mathrm{i}} \mathrm{Pr}\right)_{2}\right]$. The two O'Pr moieties are arranged trans to the neutral OMe groups; both $\mathrm{Ti}$ - O'Pr distances are shorter than the analogous bonds in Type $\mathrm{A}$ and $\mathrm{B}$ complexes (Table S3). Both imine bonds are ca. 1.27 $\AA$ and, as expected, are slightly shorter than coordinated analogues. Interestingly, Johnson and co-workers reported that an adamantyl imine substituted complex as the least sterically congested, Type I, coordination. ${ }^{26}$ In contrast, here when the adamantyl imine substituted complex adopts a Type $C$ structure which stabilizes the most sterically congested ligands. Analysis of the CSD suggests that Type B and C coordination modes are the first examples of their kind regardless of the metal center. While O-O chelation has been previously observed, in general O-O chelated phenoxy-imines required protonation of either the alkoxide or the imine nitrogen, thus forming a zwitterionic or neutral ligand, rather than the anionic ligands seen here. ${ }^{32}$

In order to investigate whether the solid state structures are maintained in solution the complexes were characterized using ${ }^{1} \mathrm{H}$ NMR spectroscopy. Complex $\left[\left(\mathrm{L}_{1}\right)_{2} \mathrm{Ti}\left(\mathrm{O}^{\mathrm{P} P r}\right)_{2}\right]$, Type $\mathrm{A}-\mathrm{I}$ in the solid state, shows resonances at lower chemical shifts compared to the free ligand. In particular, upon coordination the imine $\mathrm{CH}$ resonance is observed at lower chemical shift $(8.23 \mathrm{ppm})$ and broadens significantly (Fig. S25). The peak broadening is resolved at low temperature $\left(-80^{\circ} \mathrm{C}\right)$ and a single set of well-defined peaks are observed (Fig. S28). [(L4)2 $\left.\mathrm{Ti}\left(\mathrm{O}^{\prime} \mathrm{Pr}\right)_{2}\right]$, Type B, shows a single, broadened $\mathrm{CH}$ imine peak $(8.55 \mathrm{ppm})$ at higher chemical shift compared to the free ligand (8.34 ppm) (Fig. S26). The broadening is attributed to rapid equilibration between two asymmetrically bound ligands, vide infra. Indeed, previous studies of bis(phenoxy-imine)Ti(IV) complexes showed a similar resolution of fluxional processes at low temperatures. ${ }^{26}$ The imine substituent signals (2,6-di-isopropyl-phenyl) show broadened isopropyl resonances (3.0 ppm) which suggests restricted rotation in solution. Complexes $\left[\left(\mathrm{L}_{6}-\mathrm{L}_{8}\right)_{2} \mathrm{Ti}\left(\mathrm{O}^{\mathrm{i}} \mathrm{Pr}\right)_{2}\right]$, Type $\mathrm{C}$, all display the same general features in their ${ }^{1} \mathrm{H}$ NMR spectra. In each case, the imine $\mathrm{CH}$ resonance is at higher chemical shift compared to the free ligand, but the OMe resonance is at lower chemical shift (Figure S27). Over the series, the imine proton chemical shift is indicative of the coordination type, with values decreasing in the order: Type $C>$ Type $B>$ Type $A$.

VT NMR spectroscopy was used to characterize complexes [( $\left.\left.\mathrm{L}_{1}\right)_{2} \mathrm{Ti}_{\mathbf{T}}\left(\mathrm{O}^{\prime} \mathrm{Pr}\right)_{2}\right]$ (Type A-I),

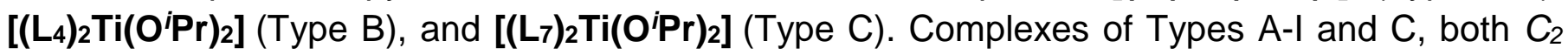


symmetric, showed little change to the spectra upon cooling (Figs. S28 and S30). In contrast, the spectrum for structure Type B underwent significant changes on cooling (Fig. 2). At room temperature, a single broadened set of signals was observed and but at $-80^{\circ} \mathrm{C}$, two imine signals were observed at $\sim 8.75$ and $8.3 \mathrm{ppm}$, integrating to one proton each. These peaks are assigned to the different imine resonances for the $\mathrm{N}-\mathrm{O}$ and $\mathrm{O}-\mathrm{O}$ chelates. The assignment is supported by a similar chemical shift for the $\mathrm{N}-\mathrm{O}$ imine resonance to that observed for Type A complexes, 8.3 $\mathrm{ppm}$, and by the value for the $\mathrm{O}-\mathrm{O}$ chelate being close to those observed for Type $\mathrm{C}$ complexes, $\sim 8.7 \mathrm{ppm}$. Furthermore, the reduced complex symmetry at low temperature results in a significantly more complex aromatic region, as well as the splitting of the methoxy and isopropyl peaks. Overall, the VT-NMR data indicate that Type B coordination is retained in solution, and at room temperature averaged signals arise from dynamic ligand exchange. It should also be noted that at low temperature several additional low intensity signals are observed throughout the spectrum and these may be attributed either to restricted $\mathrm{N}-\mathrm{Ar}$ bond rotation, residual equilibration or to minor populations of other structures (e.g Types A-II or Type C) (Fig. S29).

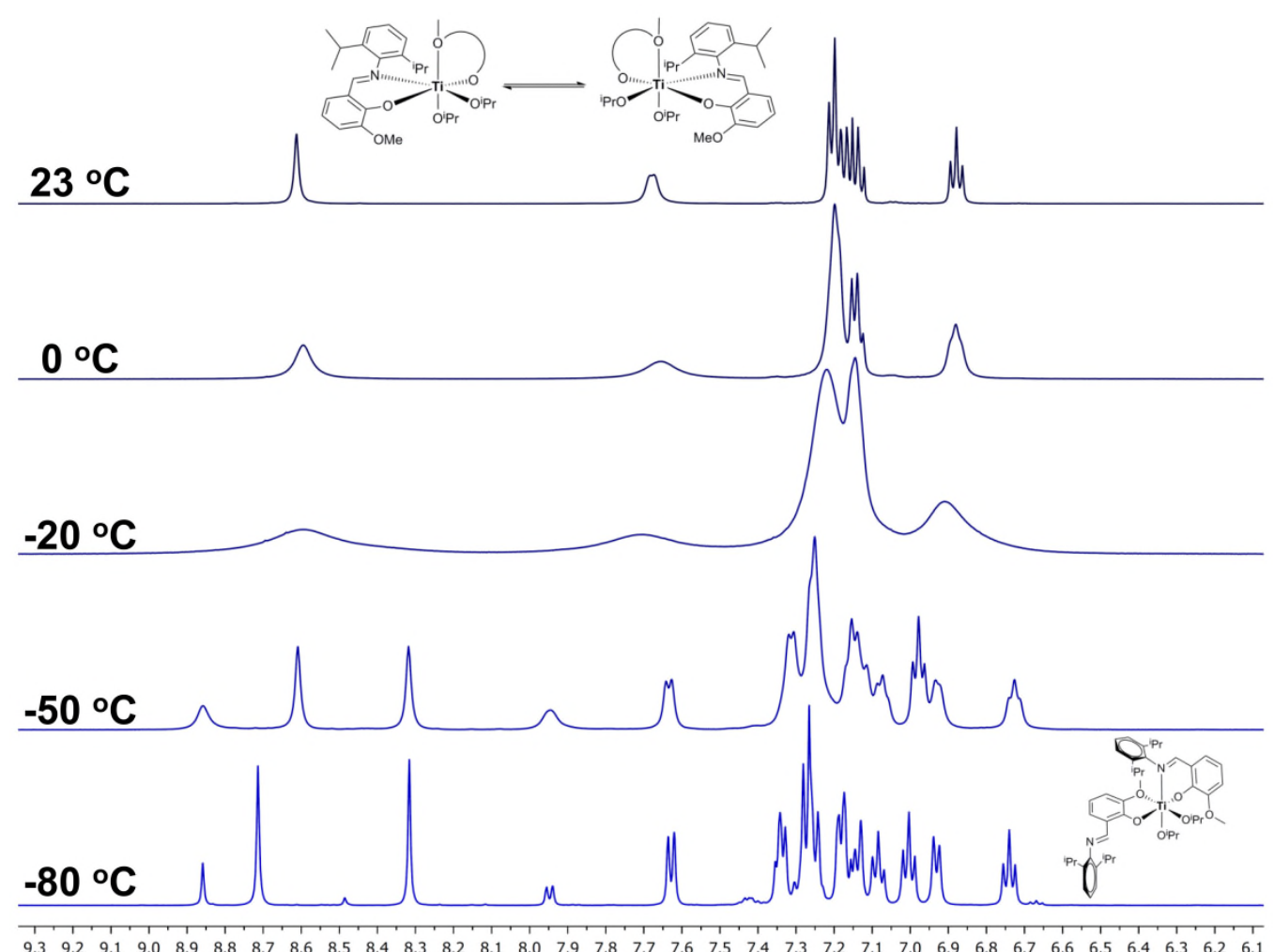

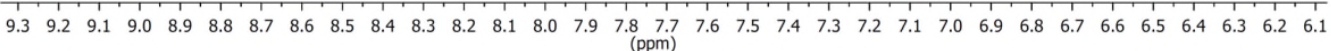

Figure 2. Variable temperature NMR spectra of selected regions, for $\left[\left(\mathrm{L}_{4}\right)_{2} \mathbf{T i}\left(\mathbf{O}^{\prime} \mathbf{P r}\right)_{2}\right]$ in $d^{\beta}-\mathrm{THF}(500 \mathrm{MHz})$.

The structure of complex $\left[\left(\mathrm{L}_{4}\right)_{2} \mathrm{Ti}\left(\mathrm{O}^{\prime} \mathrm{Pr}\right)_{2}\right]$ was also investigated at higher temperatures, by heating

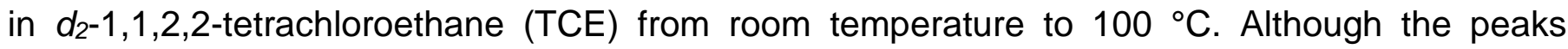
sharpened slightly there was not any significant change in the chemical shifts (Fig. S31). Additionally, the spectrum remained unchanged both after being held at $100^{\circ} \mathrm{C}$ for $24 \mathrm{~h}$, in TCE, (Fig. S32) or after being kept at $70{ }^{\circ} \mathrm{C}$, for $5 \mathrm{~h}$, in $d_{8}$-THF, (Fig. S33). The temperature and solvent stability assessment is important since polymerizations are conducted at elevated temperatures. 


\section{Polymerization Catalysis}

The series of complexes were tested as initiators for the ring-opening polymerization of $\varepsilon$ caprolactone (CL). Polymerizations were conducted both in toluene solution (1:200 [cat]:[CL], $1 \mathrm{M}$ $[\mathrm{CL}$; Table 1) and using neat conditions (1:200 [cat]:[CL] or 1:1000 [cat]:[CL]; Table S1). Catalysts $\left[\left(\mathrm{L}_{1}\right)_{2} \mathrm{Ti}\left(\mathrm{O}^{\prime} \mathrm{Pr}\right)_{2}\right]$ and $\left[\left(\mathrm{L}_{2}\right)_{2} \mathrm{Ti}\left(\mathrm{O}^{\prime} \mathrm{Pr}\right)_{2}\right]$ were both able reach high conversions, under either set of conditions, but are comparably slow (taking $24 \mathrm{~h}$ to reach complete conversion in toluene). Catalysts $\left[\left(\mathrm{L}_{4}-8\right)_{2} \mathrm{Ti}\left(\mathrm{O}^{\mathrm{i}} \mathrm{Pr}\right)_{2}\right]$ are also active and, in some cases, are several times faster than $\left[\left(\mathrm{L}_{1,2}\right)_{2} \mathrm{Ti}\left(\mathrm{O}^{\mathrm{i}} \mathrm{Pr}\right)_{2}\right]$. For example, $\left[\left(\mathrm{L}_{4}\right)_{2} \mathrm{Ti}\left(\mathrm{O}^{\mathrm{P}} \mathrm{Pr}\right)_{2}\right]$ resulted in complete conversion within $4 \mathrm{~h}$, while $\left[\left(\mathrm{L}_{6-8}\right)_{2} \mathrm{Ti}\left(\mathrm{O}^{\mathrm{P}} \mathrm{Pr}\right)_{2}\right]$ reached full conversion in just $2 \mathrm{~h}$.

All the initiators produced PCL showing a monomodal molar mass distribution and with relatively narrow dispersity values. The experimentally determined molar mass values (GPC) are in good agreement with values calculated on the basis of two initiating sites per complex (i.e. both isopropoxide ligands initiate). The complexes also enable controlled polymerization as evidenced by a linear evolution of molar mass vs. conversion (Figs. S39-41).

Table 1: Ring-opening polymerization data of $\mathrm{CL}$ from $\left[\left(\mathrm{L}_{1-8}\right)_{2} \mathrm{Ti}\left(\mathrm{O}^{\mathrm{i}} \mathrm{Pr}\right)_{2}\right]$ in toluene solution.

\begin{tabular}{|c|c|c|c|c|c|c|c|}
\hline Entry & Catalyst $^{a}$ & $\begin{array}{c}\text { Time } \\
\text { (h) }\end{array}$ & $\begin{array}{c}\text { CL Conv. } \\
(\%)^{c}\end{array}$ & $\begin{array}{c}M_{n} \\
(\text { exp })^{d}\end{array}$ & $\begin{array}{c}M_{n} \\
\text { (calc) }\end{array}$ & $\bar{D}$ & $\begin{array}{c}\text { Coordination } \\
\text { Type }\end{array}$ \\
\hline 1 & {$\left[\left(\mathrm{~L}_{1}\right)_{2} \mathrm{Ti}\left(\mathrm{O}^{\mathrm{i}} \mathrm{Pr}\right)_{2}\right]$} & 24 & 99 & 9,460 & 11,300 & 1.13 & A-I \\
\hline 2 & {$\left[\left(\mathrm{~L}_{2}\right)_{2} \mathrm{Ti}\left(\mathrm{O}^{\mathrm{i}} \mathrm{Pr}\right)_{2}\right]$} & 24 & 99 & 8,780 & 11,300 & 1.20 & A-I \\
\hline 3 & {$\left[\left(\mathrm{~L}_{3}\right)_{2} \mathrm{Ti}\left(\mathrm{O}^{\mathrm{i}} \mathrm{Pr}\right)_{2}\right]$} & 9 & 90 & 8,890 & 10,300 & 1.27 & A-II \\
\hline 4 & {$\left[\left(\mathrm{~L}_{4}\right)_{2} \mathrm{Ti}\left(\mathrm{O}^{\mathrm{i}} \mathrm{Pr}\right)_{2}\right]$} & 4 & 99 & 13,100 & 11,300 & 1.27 & B \\
\hline 5 & {$\left[\left(\mathrm{~L}_{5}\right)_{2} \mathrm{Ti}\left(\mathrm{O}^{\mathrm{i}} \mathrm{Pr}\right)_{2}\right]$} & 4 & 73 & 10,900 & 8,330 & 1.10 & B \\
\hline 6 & {$\left[\left(\mathrm{~L}_{6}\right)_{2} \mathrm{Ti}\left(\mathrm{O}^{\mathrm{i}} \mathrm{Pr}\right)_{2}\right]$} & 2 & 99 & 16,100 & 11,300 & 1.41 & C \\
\hline 7 & {$\left[\left(\mathrm{~L}_{7}\right)_{2} \mathrm{Ti}\left(\mathrm{O}^{\mathrm{i}} \mathrm{Pr}\right)_{2}\right]$} & 2 & 99 & 13,100 & 11,300 & 1.09 & C \\
\hline 8 & {$\left[\left(\mathrm{~L}_{8}\right)_{2} \mathrm{Ti}\left(\mathrm{O}^{\mathrm{i} P r}\right)_{2}\right]$} & 2 & 99 & 12,200 & 11,300 & 1.44 & C \\
\hline $9^{b}$ & {$\left[\left(\mathrm{~L}_{4}\right)_{2} \mathrm{Ti}\left(\mathrm{O}^{\mathrm{i} P r}\right)_{2}\right]$} & 0.10 & 90 & 12,100 & 10,300 & 1.63 & B \\
\hline $10^{\mathrm{b}}$ & {$\left[\left(\mathrm{L}_{7}\right)_{2} \mathrm{Ti}\left(\mathrm{O}^{\mathrm{i} P r}\right)_{2}\right]$} & 0.12 & 90 & 13,600 & 10,300 & 1.46 & C \\
\hline $11^{f}$ & {$\left[\mathrm{Ti}\left(\mathrm{O}^{\prime} \mathrm{Pr}\right)_{4}\right]$} & 0.05 & 95 & 19,800 & & 2.02 & \\
\hline
\end{tabular}

${ }^{a}$ Polymerization conditions: $[\mathrm{cat}]:[\mathrm{CL}]=1: 200,[\mathrm{CL}]=1 \mathrm{M}$, toluene, $80^{\circ} \mathrm{C} ;{ }^{b}[\mathrm{cat}]:[\mathrm{CL}]=1: 200$, Unpurified $\mathrm{CL}$, neat, $140{ }^{\circ} \mathrm{C}$, in air; ${ }^{\circ} \mathrm{Calculated}$ from the ${ }^{1} \mathrm{H}$ NMR spectrum of the crude polymer, by comparison of the integrals assigned to CL (4.20 ppm) and PCL (4.07 ppm); ' Measured by GPC, in THF and calibrated using PS standards; $M_{n}$ values are reported after correction (multiplication by 0.56); ${ }^{33}{ }^{\text {e }} M_{n(\text { calc }}=$ (conversion/100) $\times$ loading/[2] $\times \operatorname{RMM}(\mathrm{CL}){ }^{f}$ From ref. 36. Conditions: [cat]:[CL] $=1: 212, \mathrm{CL}$, neat, $100{ }^{\circ} \mathrm{C}$, in air.

On the basis of the point kinetic measurements, the activity order is $\left[\left(\mathrm{L}_{8}\right)_{2} \mathrm{Ti}\left(\mathrm{O}^{\mathrm{i}} \mathrm{Pr}\right)_{2}\right] \sim$ $\left[\left(\mathrm{L}_{7}\right)_{2} \mathrm{Ti}\left(\mathrm{O}^{\prime} \mathrm{Pr}\right)_{2}\right] \sim\left[\left(\mathrm{L}_{6}\right)_{2} \mathrm{Ti}\left(\mathrm{O}^{\prime} \mathrm{Pr}\right)_{2}\right]>\left[\left(\mathrm{L}_{5}\right)_{2} \mathrm{Ti}\left(\mathrm{O}^{\prime} \mathrm{Pr}\right)_{2}\right] \sim\left[\left(\mathrm{L}_{4}\right)_{2} \mathrm{Ti}\left(\mathrm{O}^{\prime} \mathrm{Pr}\right)_{2}\right]>\left[\left(\mathrm{L}_{3}\right)_{2} \mathrm{Ti}\left(\mathrm{O}^{\prime} \mathrm{Pr}\right)_{2}\right]>$ $\left[\left(\mathrm{L}_{2}\right)_{2} \mathrm{Ti}\left(\mathrm{O}^{\mathrm{i}} \mathrm{Pr}\right)_{2}\right] \sim\left[\left(\mathrm{L}_{1}\right)_{2} \mathrm{Ti}\left(\mathrm{O}^{\mathrm{i}} \mathrm{Pr}\right)_{2}\right]$ or, in terms of coordination chemistry, Type $\mathrm{C}>$ Type $\mathrm{B}>$ Type A-II > Type A-l. The rates are generally slower than the homoleptic $\mathrm{Ti}(\mathrm{OiPr}) 4,{ }^{36}$ although comparisons are complicated by different reaction conditions (temperature) and uncertainties regarding number of initiating groups. 
To gain insight into the influence of the coordination type, polymerization kinetic evaluations were undertaken using selected examples of each structure, i.e. complexes $\left[\left(\mathrm{L}_{3}\right)_{2} \mathrm{Ti}\left({ }^{\mathrm{O}} \mathrm{OPr}\right)_{2}\right]$, [(L4) $\left.{ }_{2} \mathrm{Ti}\left(\mathrm{O}^{\prime} \mathrm{Pr}\right)_{2}\right]$, and [( $\left.\left.\mathrm{L}_{8}\right)_{2} \mathrm{Ti}\left(\mathrm{O}^{\prime} \mathrm{Pr}\right)_{2}\right]$ (Fig. 3). All polymerizations showed good control, with molar mass values increasing linearly with conversion and showing narrow dispersity throughout the reaction (Figs. S42-44). All three catalysts showed rates that were first order in monomer concentration and the reactivity trends are retained with Type $C>$ Type $B>$ Type A. Specifically, Type $C$ is twice as fast as Type B, which is three times faster than Type A-II. A sample of low molar mass PCL from each polymerization was analyzed by MALDI-ToF and showed only isopropoxide chain end groups (Figs. S45-47). Thus, all catalysts enchain by a coordinationinsertion mechanism and the particular coordination chemistry significantly influences the polymerization rate.

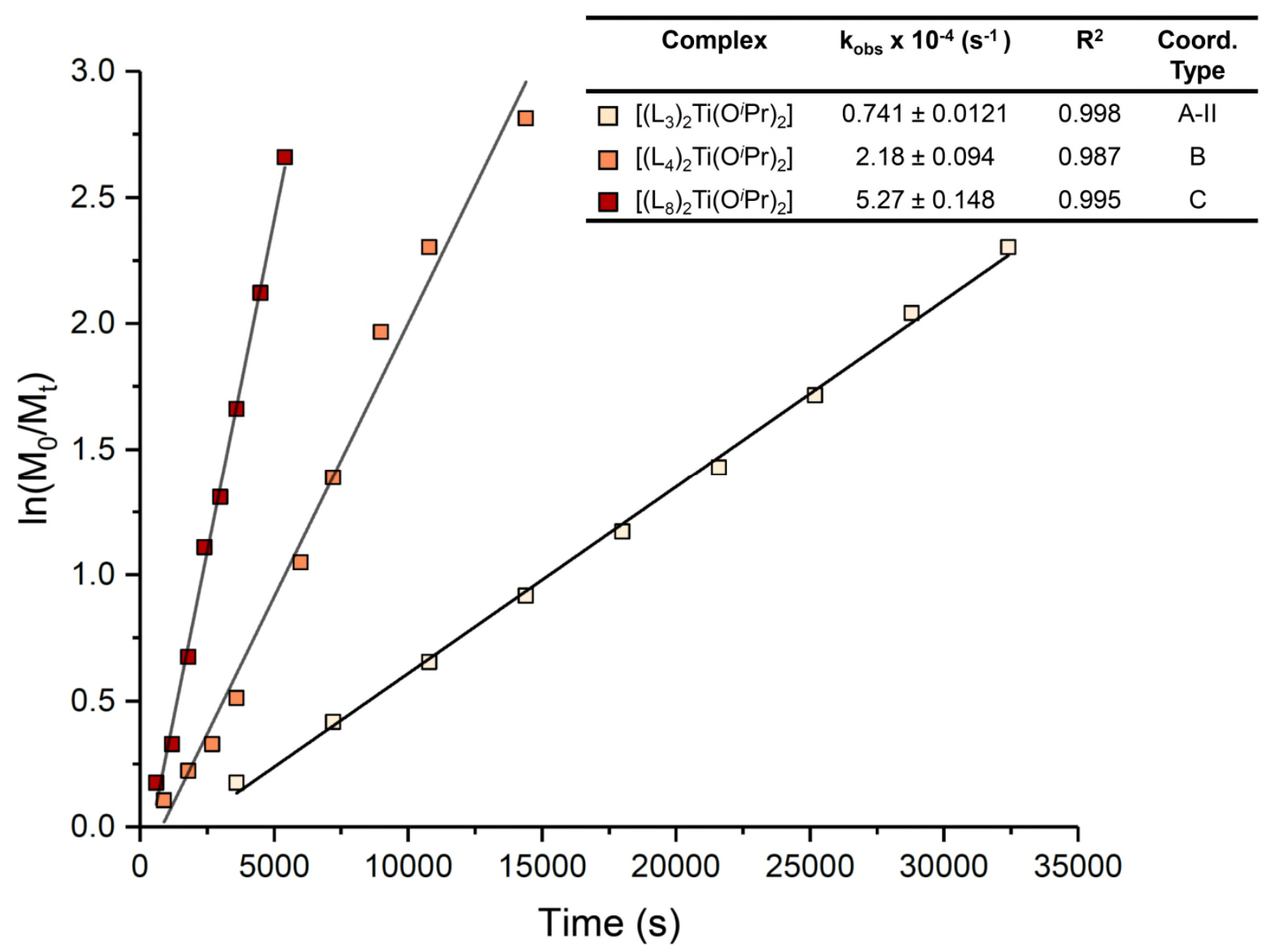

Figure 3. Plots of $\ln \left(\mathrm{M}_{0} / \mathrm{M}_{t}\right)$ vs. time for three different catalysts, each selected as an exemplar of a particular coordination type. Polymerization conditions: $\left[\right.$ cat]:[CL] $=1: 200,[C L]=1.0 \mathrm{M}$, toluene, $80^{\circ} \mathrm{C}$.

Polymerizations were also conducted in neat $\mathrm{CL}$ and the reactivity trends were similar to those obtained in toluene, however, under these conditions the increased viscosity results in diffusion limitations. As such, the molar mass values are higher than expected, particularly at higher conversions. Selected catalysts were also tested under conditions more analogous to those used industrially, i.e. using neat $C L$, at elevated temperature and using lower catalyst loading $(1: 1000$, [cat]:[CL]): all catalysts maintained activity and control (Table S1). One advantage of these titanium catalysts may be an improved resistance to decomposition in air, particularly compared 
to other organometallic initiators. Indeed, the high stability of other bis(phenoxy-imine) Ti(IV) alkoxide complexes towards hydrolysis was already described. ${ }^{34-35}$ To test the resilience of the new catalysts, polymerizations were conducted using unpurified $\mathrm{CL}$, preheated to $140{ }^{\circ} \mathrm{C}$ for 15 minutes to remove residual water. ${ }^{36}$ The catalyst, dissolved in minimal toluene, was added and the polymerization vessel was open to the atmosphere. Complete monomer conversion was achieved within minutes and produced PCL with predictable molar mass and narrow dispersity (Table 1, Entries 9 and 10).

PCL is applied in the preparation of new medical devices and potentially for future applications in elastomer, coating and sealant areas. ${ }^{14,37}$ In contrast, macrolactone ROP provides access to polyesters with thermal properties approaching those of some grades of polyethene. ${ }^{38-43}$ As such, these long-chain aliphatic polyesters may be substitutes for pervasive petro-polymers and an attractive method to prepare them is by the ring-opening polymerization of macrolactones. ${ }^{38-39,44-}$ ${ }^{46}$ So far, the range of catalysts investigated for macrolactone ROP is more limited and activities tend to be significantly lower than equivalent reactions with CL. ${ }^{44}$ Thus, it was of interest to evaluate these $\mathrm{Ti}(\mathrm{IV})$ catalysts for the ring opening polymerization of $\omega$-pentadecalactone (PDL). Polymerizations were conducted either in toluene or in the melt at $100{ }^{\circ} \mathrm{C}$ (Table 2, S2). In all cases the activities were lower than in $\mathrm{CL}$ ROP, but the overall activity trend remained the same: Type $\mathrm{C}>$ Type $\mathrm{B}>$ Type A-II > Type A-I.

The resulting polyesters showed molar mass values higher than expected, although it should be noted that the molar mass values determined by GPC are calibrated with polystyrene and are uncorrected. Previous studies into PDL ROP also yielded polyesters showing higher molar mass values than expected and this was rationalized by limited catalyst solubility under the polymerization conditions. ${ }^{46}$ In contrast, the Ti(IV) catalysts remain entirely soluble both in toluene and in the PDL melt. Catalyst deactivation is also unlikely since a polymerization in the melt, using freshly distilled PDL, gave similarly high molar mass values to unpurified PDL (Table S2, Entries 5 and 6). Furthermore, these catalysts are more tolerant to low levels of water, even at elevated temperatures, than other organometallic ROP catalysts. Thus, the discrepancy between experimental and calculated molar masses appears most likely to result from GPC calibration methods, with future work necessary to determine the Mark Houwink parameters for PPDL.

Table 2: PDL Ring-opening polymerization using catalysts $\left[\left(\mathrm{L}_{1-8}\right)_{2} \mathrm{Ti}\left(\mathrm{O}^{\mathrm{i}} \mathrm{Pr}\right)_{2}\right]$

\begin{tabular}{|c|c|c|c|c|c|c|c|}
\hline Entry & Catalyst $^{a}$ & $\begin{array}{c}\text { Time } \\
\text { (h) }\end{array}$ & $\begin{array}{l}\text { Conv. } \\
(\%)^{b}\end{array}$ & $\begin{array}{c}M_{n} \\
(\exp )^{c}\end{array}$ & $\begin{array}{c}M_{n} \\
\text { (calc) }\end{array}$ & $\Phi$ & $\begin{array}{c}\text { Coordination } \\
\text { Type }\end{array}$ \\
\hline 1 & {$\left[\left(\mathrm{~L}_{1}\right)_{2} \mathrm{Ti}^{\mathrm{T}}\left(\mathrm{O}^{\mathrm{i}} \mathrm{Pr}\right)_{2}\right]$} & 24 & 5 & - & & - & A-I \\
\hline 2 & {$\left[\left(\mathrm{~L}_{3}\right)_{2} \mathrm{Ti}\left(\mathrm{O}^{\mathrm{i}} \mathrm{Pr}\right)_{2}\right]$} & 24 & 27 & 7,680 & 3,250 & 1.49 & A-II \\
\hline 3 & {$\left[\left(\mathrm{~L}_{4}\right)_{2} \mathrm{Ti}\left(\mathrm{O}^{\mathrm{P} P r}\right)_{2}\right]$} & 48 & 72 & 21,700 & 8,650 & 1.79 & B \\
\hline 4 & {$\left[\left(\mathrm{~L}_{5}\right)_{2} \mathrm{Ti}\left(\mathrm{O}^{\mathrm{P} P r}\right)_{2}\right]$} & 24 & 32 & 3,430 & 3,850 & 1.89 & B \\
\hline 5 & {$\left[\left(\mathrm{~L}_{6}\right)_{2} \mathrm{Ti}\left(\mathrm{O}^{\mathrm{i}} \mathrm{Pr}\right)_{2}\right]$} & 24 & 96 & 36,500 & 11,500 & 1.69 & C \\
\hline 6 & {$\left[\left(\mathrm{~L}_{7}\right)_{2} \mathrm{Ti}\left(\mathrm{O}^{\prime} \mathrm{Pr}\right)_{2}\right]$} & 24 & 47 & 14,800 & 5,650 & 1.70 & C \\
\hline 7 & {$\left[\left(\mathrm{~L}_{8}\right)_{2} \mathrm{Ti}\left(\mathrm{O}^{\mathrm{i}} \mathrm{Pr}\right)_{2}\right]$} & 72 & 95 & 6,960 & 11,400 & 2.15 & C \\
\hline
\end{tabular}

${ }^{a}$ [cat]:[PDL] $=1: 100, \quad[\mathrm{PDL}]=1 \mathrm{M}$ in toluene, $100{ }^{\circ} \mathrm{C}, \mathrm{N}_{2},{ }^{b} \mathrm{Calculated}$ from the ${ }^{1} \mathrm{H}$ NMR spectrum of the crude polymer, by comparison of the integrals assigned to PDL (4.14 ppm) and PPDL (4.07 ppm). 
${ }^{c}$ Measured by GPC, in $\mathrm{CHCl}_{3}$ and calibrated using PS standards and uncorrected. ${ }^{d} M_{n \text { (calc) }}=$ (conversion/100) x loading/[2] x RMM(PDL)

Following the successful ROP of both $\mathrm{CL}$ and $\mathrm{PDL}$, terpolymerization reactions were investigated as a means to form poly(CL-Co-PDL). Since the rates of CL ROP are much faster than PDL ROP, a gradient or block copolymer might be expected. Nonetheless, previous investigations into terpolymerizaitons using these monomers resulted in the formation of random copolymers. ${ }^{44} \mathrm{~A}$ terpolymerization reaction, using $\left[\left(\mathrm{L}_{6}\right)_{2} \mathrm{Ti}\left(\mathrm{O}^{\circ} \mathrm{Pr}\right)_{2}\right]$, was conducted in toluene, at $100{ }^{\circ} \mathrm{C}(1: 100: 100$ $[\mathrm{cat}] /[\mathrm{CL}] /[\mathrm{PDL}]$, [lactones] $=1 \mathrm{M})$. The polymerization was monitored by aliquots removed after 2.5 and $24 \mathrm{~h}$ of reaction. After 2.5 hours, $64 \%$ conversion was achieved and the polymer was mostly comprised of PCL, as evident from the relative intensity of the a-methylene junction units in ${ }^{13} \mathrm{C}\left\{{ }^{1} \mathrm{H}\right\}$ NMR spectrum $(65-63 \mathrm{ppm}$, Fig. S50). After 24 hours, all monomers were fully converted and a random polymer was indicated. The copolymer was analyzed using DSC and showed a melting point at $74.6{ }^{\circ} \mathrm{C}$ (Fig. S51), which was slightly higher than previous reports perhaps due to molar mass differences. ${ }^{44}$

\section{Polymerization Mechanism}

The catalysts' reactivity trend (Type C > Type B > Type A) appears to correlate with reduced steric hindrance at the Ti(IV) active site. As steric bulk of the substituents attached to the imine increases, so complexes tend to adopt structures with O-O chelation thus placing the sterically hindered substituents further from the active site. In an attempt to qualify this notion, Solid-g analysis ${ }^{47-48}$ of the crystal structures of $\left[\left(\mathrm{L}_{1}\right)_{2} \mathrm{Ti}\left(\mathrm{O}^{\mathrm{i}} \mathrm{Pr}\right)_{2}\right],\left[\left(\mathrm{L}_{4}\right)_{2} \mathrm{Ti}\left(\mathrm{O}^{\mathrm{i}} \mathrm{Pr}\right)_{2}\right]$ and $\left[\left(\mathrm{L}_{6}\right)_{2} \mathrm{Ti}\left(\mathrm{O}^{\mathrm{i}} \mathrm{Pr}\right)_{2}\right]$ was undertaken but regardless of the specific coordination mode the Ti(IV) centre is always $96-98 \%$ shielded by ligands. Whilst this analysis does not rule out the importance of steric hindrance, particularly surrounding the growing polymer chain, it does indicate that other factors warrant consideration. In terms of the polymerization mechanism, lactone ROP generally occurs by the well-known coordination-insertion process, here polymer chain end-group analysis supports this pathway. An interesting consideration is the influence the ancillary ligands may exert over monomer coordination. Previously, Chen and co-workers invoked mechanisms resulting in formation of 7-coordinate lactone coordinated intermediates in ROP using bis(alkoxide)bis(phenoxy-imine)Ti(IV) catalysts. ${ }^{49}$ The proposal was based on structure-activity results but there was no direct evidence for the associated 7-coordinate intermediate. In contrast, we propose a dissociative type coordination insertion mechanism, whereby one of the neutral donor atoms from the Schiff base ligand is de-coordinated from the metal to form a vacant site prior to monomer coordination (Scheme 3 for an illustration of the pathway). Considering the structure-activity data, higher rates are observed for ligands adopting the more labile five membered $\mathrm{O}-\mathrm{O}$ chelates, which show weaker Ti-O bonds. Accordingly, lower rates are observed from ligands adopting the six membered $\mathrm{N}-\mathrm{O}$ chelates, which have stronger Ti-N bonds. Thus, the most active complexes may show greater ligand dissociation (Ti-O bond cleavage) which accelerates monomer coordination and formation of the activated complex. Although there is no direct spectroscopic evidence for such ligand hemi-lability, it could be occurring more rapidly than NMR timescales and/or accelerated in the presence of coordinating monomer. Additionally, the 
polymer molar mass studies indicate that both alkoxide groups initiate and that two polymer chains growing per Ti(IV) centre. Such a ligand dissociation pathway would be much more likely to accommodate the steric demands of two propagating sites, with associated dissociation/coordination and insertion reactions, compared with higher coordinate associative type intermediates. We wish to emphasize that prior to a complete kinetic evaluation it would be premature to speculate further upon the intimate details of chain growth. Rather the overall structure-activity data demonstrate the potential to exploit ligand dissociation and coordination modes to enhance catalytic activity.

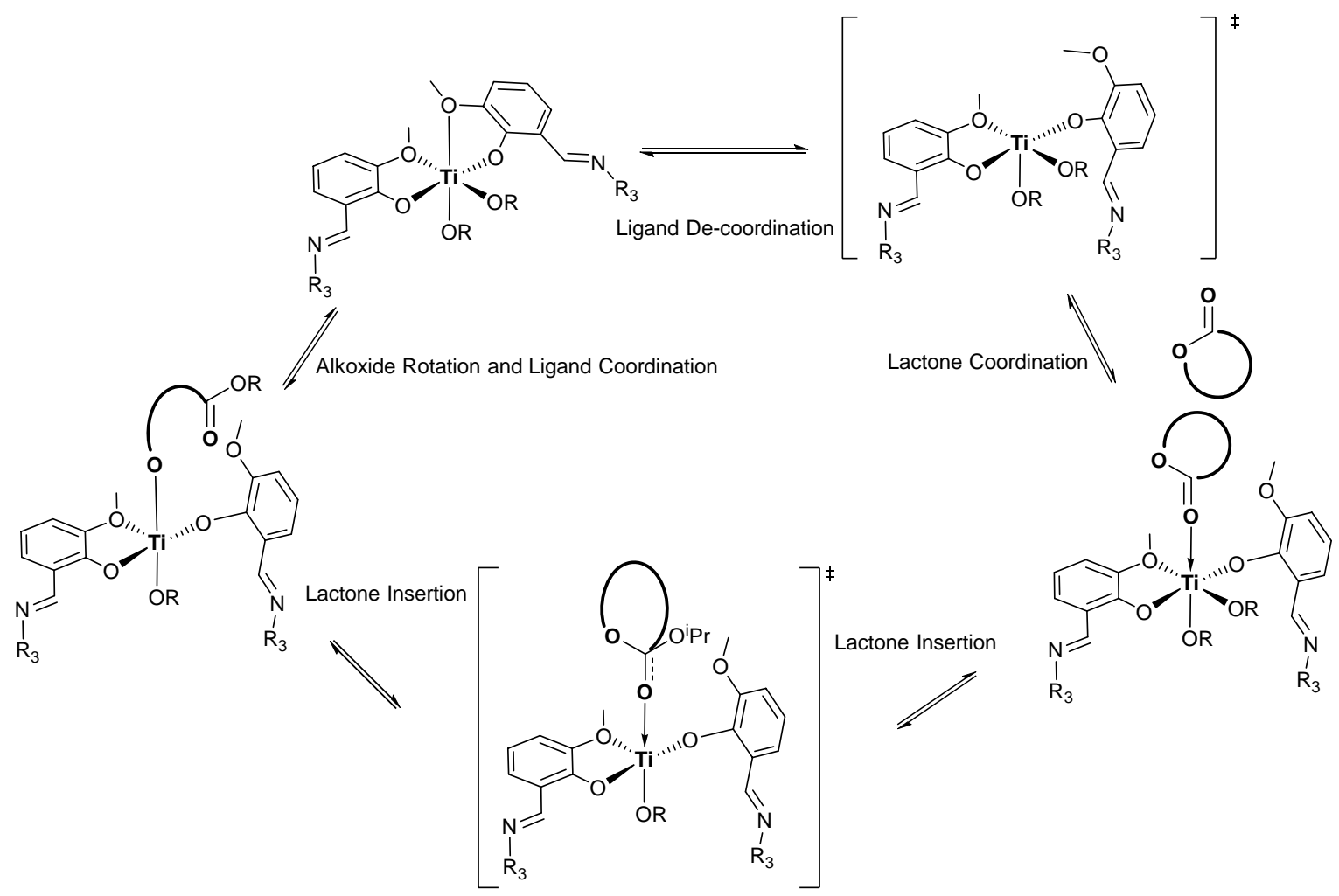

Scheme 3: Proposed Dissociative Coordination-Insertion Polymerization pathway for new Ti(IV) catalysts. Where $\mathrm{R}=$ iso-propyl (initiator) and polymer chain (propagation).

\section{Conclusion}

Eight new o-vanillin derived phenoxy-imine ligands and bis(phenoxy-imine)titanium(IV) complexes were prepared. The steric bulk of the ligand, in particular the imine nitrogen substituents, influences the coordination chemistry in the complexes. The complexes adopt three major coordination modes, each featuring $\mathrm{N}-\mathrm{O}$ and/or O-O chelation. These different coordination modes influence the catalytic activity in lactone ring-opening polymerizations with the most active catalysts showing $\mathrm{O}-\mathrm{O}$ chelation by both ligands. It is proposed that increased steric hindrance at the imine nitrogen substituent favor formation of 5-membered $\mathrm{O}-\mathrm{O}$ chelation, which in turn affects the lability of the ligand around the Ti(IV) active site, thereby resulting in faster rates. 
Overall, this work highlights the importance and relevance of ligand coordination modes as a viable means to control polymerization activity. In general, other Group IV catalysts show outstanding performance in catalysis and exploration of these catalysts for other processes is warranted, in particular for alkene polymerization catalysis. Given the ease of $o$-vanillin ligand and complex preparation, and the means to qualify coordination mode, studies into coordination chemistry at metal centers are recommended. In particular, using these ligands to prepare complexes with other transition metals and main group elements, particularly those in higher oxidation states $\mathrm{M}(\mathrm{III} / \mathrm{IV})$, should provide access to new ring-opening polymerization catalysts and allow better understanding of how to exploit coordination geometry to enhance rates.

\section{Associated Contents}

Supporting information contains complete experimental details, full ${ }^{1} \mathrm{H}$ and ${ }^{13} \mathrm{C}\left\{{ }^{1} \mathrm{H}\right\} \mathrm{NMR}$ assignments of $\left[\left(\mathrm{L}_{1-8}\right)_{2} \mathrm{Ti}\left(\mathrm{O}^{\mathrm{i} P r}\right)_{2}\right]$, X-ray crystallographic information files (CIF), polymer MALDI-ToF MS data, and representative GPC chromatograms.

CCDC 1856548-1856555 contains the supplementary crystallographic data for this paper. The data can be obtained free of charge from The Cambridge Crystallographic Data Centre via www.ccdc.cam.ac.uk/structures.

\section{Acknowledgements}

The authors acknowledge Siam Cement Group (SCG) Chemicals Co., Ltd for funding.

\section{References}

1. Decortes, A.; Castilla, A. M.; Kleij, A. W., Salen-Complex-Mediated Formation of Cyclic Carbonates by Cycloaddition of CO2 to Epoxides. Angew. Chem. Int. Ed. 2010, 49 (51), 9822-9837.

2. Cozzi, P. G., Metal-Salen Schiff base complexes in catalysis: practical aspects. Chem. Soc. Rev. 2004, 33 (7), 410-421.

3. Darensbourg, D. J., Making Plastics from Carbon Dioxide: Salen Metal Complexes as Catalysts for the Production of Polycarbonates from Epoxides and CO2. Chem. Rev. 2007, 107 (6), 2388-2410.

4. Gupta, K. C.; Sutar, A. K., Catalytic activities of Schiff base transition metal complexes. Coord. Chem. Rev. 2008, 252 (12), 1420-1450.

5. Jacobsen, E. N., Asymmetric Catalysis of Epoxide Ring-Opening Reactions. Acc. Chem. Res. 2000, $33(6), 421-431$.

6. Jones, D. J.; Gibson, V. C.; Green, S. M.; Maddox, P. J.; White, A. J. P.; Williams, D. J., Discovery and optimization of new chromium catalysts for ethylene oligomerization and polymerization aided by high-throughput screening. J. Am. Chem. Soc. 2005, 127 (31), 11037-11046.

7. Kim, I.; Kwak, C. H.; Kim, J. S.; Ha, C. S., Ethylene oligomerizations to low-carbon linear alphaolefins by structure modulated phenoxy-imine nickel(II) complexes combined with aluminum sesquichloride. Appl. Catal., A 2005, $287(1)$, 98-107.

8. Kinoshita, S.; Kawamura, K.; Fujita, T., Early-Transition-Metal Catalysts with Phenoxy-Imine-Type Ligands for the Oligomerization of Ethylene. Chem. - Asian J. 2011, 6 (2), 284-290.

9. $\quad$ Kirillov, E.; Roisnel, T.; Razavi, A.; Carpentier, J. F., Chromium(III) Complexes of Sterically Crowded Bidentante $\{\mathrm{ONR}\}$ and Tridentate $\{\mathrm{ONNR}\}$ Naphthoxy-Imine Ligands: Syntheses, Structures, and Use in Ethylene Oligomerization. Organometallics 2009, 28 (8), 2401-2409.

10. Matsui, S.; Mitani, M.; Saito, J.; Tohi, Y.; Makio, H.; Matsukawa, N.; Takagi, Y.; Tsuru, K.; Nitabaru, M.; Nakano, T.; Tanaka, H.; Kashiwa, N.; Fujita, T., A Family of Zirconium Complexes Having Two Phenoxy-Imine Chelate Ligands for Olefin Polymerization. J. Am. Chem. Soc. 2001, 123, 6847-6856.

11. Parssinen, A.; Luhtanen, T.; Klinga, M.; Pakkanen, T.; Leskela, M.; Repo, T., Bis(salicylaldiminato)titanium complexes containing bulky imine substituents: Synthesis, characterization and ethene polymerization studies. Eur. J. Inorg. Chem. 2005, (11), 2100-2109. 
12. Parssinen, A.; Luhtanen, T.; Klinga, M.; Pakkanen, T.; Leskela, M.; Repo, T., Alkylphenylsubstituted bis(salicylaldiminato) titanium catalysts in ethene polymerization. Organometallics 2007, 26 (15), 3690-3698.

13. Suzuki, Y.; Tanaka, H.; Oshiki, T.; Takai, K.; Fujita, T., Titanium and Zirconium Complexes with Non-Salicylaldimine-Type Imine-Phenoxy Chelate Ligands: Syntheses, Structures, and EthylenePolymerization Behavior. Chem. - Asian J. 2006, 1 (6), 878-887.

14. Labet, M.; Thielemans, W., Synthesis of polycaprolactone: a review. Chem. Soc. Rev. 2009, 38 (12), 3484-3504.

15. Chmura, A. J.; Davidson, M. G.; Jones, M. D.; Lunn, M. D.; Mahon, M. F.; Johnson, A. F.; Khunkamchoo, P.; Roberts, S. L.; Wong, S. S. F., Group 4 Complexes with Aminebisphenolate Ligands and Their Application for the Ring Opening Polymerization of Cyclic Esters. Macromolecules 2006, 39 (21), 7250-7257.

16. Gendler, S.; Segal, S.; Goldberg, I.; Goldschmidt, Z.; Kol, M., Titanium and Zirconium Complexes of Dianionic and Trianionic Amine-Phenolate-Type Ligands in Catalysis of Lactide Polymerization. Inorg. Chem. 2006, 45 (12), 4783-4790.

17. Kim, Y.; Jnaneshwara, G. K.; Verkade, J. G., Titanium Alkoxides as Initiators for the Controlled Polymerization of Lactide. Inorg. Chem. 2003, 42 (5), 1437-1447.

18. Bakewell, C.; Fateh-Iravani, G.; Beh, D. W.; Myers, D.; Tabthong, S.; Hormnirun, P.; White, A. J. P.; Long, N.; Williams, C. K., Comparing a series of 8-quinolinolato complexes of aluminium, titanium and zinc as initiators for the ring-opening polymerization of rac-lactide. Dalton Trans. 2015, 44 (27), 1232612337.

19. Saha, T. K.; Mandal, M.; Chakraborty, D.; Ramkumar, V., Imino phenoxide complexes of group 4 metals: synthesis, structural characterization and polymerization studies. New. J. Chem. 2013, 37 (4), 949-960.

20. Fujita, T.; Kawai, K., FI Catalysts for Olefin Oligomerization and Polymerization: Production of Useful Olefin-Based Materials by Unique Catalysis. Top. Catal. 2014, 57 (10-13), 852-877.

21. Mitani, M.; Furuyama, R.; Mohri, J.-i.; Saito, J.; Ishii, S.; Terao, H.; Nakano, T.; Tanaka, H.; Fujita, T., Syndiospecific Living Propylene Polymerization Catalyzed by Titanium Complexes Having FluorineContaining Phenoxy-Imine Chelate Ligands. J. Am. Chem. Soc. 2003, 125 (14), 4293-4305.

22. Junji, S.; Makoto, M.; Jun-ichi, M.; Yasunori, Y.; Shigekazu, M.; Sei-ichi, I.; Shin-ichi, K.; Norio, K.; Terunori, F., Living Polymerization of Ethylene with a Titanium Complex Containing Two Phenoxy-Imine Chelate Ligands. Angew. Chem. Int. Ed. 2001, 40 (15), 2918-2920.

23. Tian, J.; Hustad, P. D.; Coates, G. W., A New Catalyst for Highly Syndiospecific Living Olefin Polymerization: Homopolymers and Block Copolymers from Ethylene and Propylene. J. Am. Chem. Soc. 2001, $123(21), 5134-5135$.

24. Suzuki, Y.; Inoue, Y.; Tanaka, H.; Fujita, T., Phenoxy-ether ligated Ti complexes for the polymerization of ethylene. Macromol. Rapid Commun. 2004, 25 (3), 493-497.

25. Lamberti, M.; Mazzeo, M.; Pellecchia, C., Group 4 bis(chelate) metal complexes of monoanionic bidentate $[\mathrm{E}, \mathrm{O}-]$ ligands $(\mathrm{E}=\mathrm{O}, \mathrm{S})$ : synthesis and application as a-olefin polymerization catalysts. Dalton Trans. 2009, (41), 8831-8837.

26. Johnson, A. L.; Davidson, M. G.; Lunn, M. D.; Mahon, M. F., Synthesis, Isolation and Structural Investigation of Schiff-Base Alkoxytitanium Complexes: Steric Limitations of Ligand Coordination. Eur. J. Inorg. Chem. 2006, 2006, 3088-3098.

27. Thevenon, A.; Garden, J. A.; White, A. J.; Williams, C. K., Dinuclear Zinc Salen Catalysts for the Ring Opening Copolymerization of Epoxides and Carbon Dioxide or Anhydrides. Inorg. Chem. 2015, 54 (24), 11906-15.

28. Xie, Q.-W.; Wu, S.-Q.; Liu, C.-M.; Cui, A.-L.; Kou, H.-Z., Synthesis, crystal structure and magnetic properties of dinuclear NillLnIll complexes based on a flexible polydentate ligand. Dalton Trans. 2013, 42 (31), 11227-11233.

29. Xie, Q.-W.; Wu, S.-Q.; Shi, W.-B.; Liu, C.-M.; Cui, A.-L.; Kou, H.-Z., Heterodinuclear MII-LnIII single molecule magnets constructed from exchange-coupled single ion magnets. Dalton Trans. 2014, 43 (29), 11309-11316.

30. Matsunaga, S.; Shibasaki, M., Recent advances in cooperative bimetallic asymmetric catalysis: dinuclear Schiff base complexes. Chem. Commun. 2014, 50 (9), 1044-1057. 
31. Allen, F., The Cambridge Structural Database: a quarter of a million crystal structures and rising. Acta Cryst. 2002, B58 (3 Part 1), 380-388.

32. Upadhyay, A.; Das, C.; Shanmugam, M.; Langley, S. K.; Murray, K. S.; Shanmugam, M., Electronic and Magnetic Properties of a Gadolinium(III) Schiff Base Complex. Eur. J. Inorg. Chem. 2014, 2014 (26), 4320-4325.

33. Save, M.; Schappacher, M.; Soum, A., Controlled Ring-Opening Polymerization of Lactones and Lactides Initiated by Lanthanum Isopropoxide, 1. General Aspects and Kinetics. Macromol. Chem. Phys. 2002, 203 (5-6), 889-899.

34. Peri, D.; Meker, S.; Manna, C. M.; Tshuva, E. Y., Different ortho and para Electronic Effects on Hydrolysis and Cytotoxicity of Diamino Bis(Phenolato) "Salan" Ti(IV) Complexes. Inorg. Chem. 2011, 50 (3), 1030-1038.

35. Tzubery, A.; Tshuva, E. Y., Cytotoxic Titanium(IV) Complexes of Salalen-Based Ligands. Eur. J. Inorg. Chem. 2017, 2017 (12), 1695-1705.

36. Parssinen, A.; Kohlmayr, M.; Leskela, M.; Lahcini, M.; Repo, T., Catalytic polymerization of epsilon-caprolactone in air. Polym. Chem. 2010, 1 (6), 834-836.

37. Ikada, Y.; Tsuji, H., Biodegradable polyesters for medical and ecological applications. Macromol. Rapid Commun. 2000, 21 (3), 117-132.

38. Myers, D.; Witt, T.; Cyriac, A.; Bown, M.; Mecking, S.; Williams, C. K., Ring opening polymerization of macrolactones: high conversions and activities using an yttrium catalyst. Polym. Chem. 2017, 8 (37), 5780-5785.

39. Pepels, M. P. F.; Hansen, M. R.; Goossens, H.; Duchateau, R., From Polyethylene to Polyester: Influence of Ester Groups on the Physical Properties. Macromolecules 2013, 46 (19), 7668-7677.

40. Stempfle, F.; Ortmann, P.; Mecking, S., Long-Chain Aliphatic Polymers To Bridge the Gap between Semicrystalline Polyolefins and Traditional Polycondensates. Chem. Rev. 2016, 116 (7), 45974641.

41. Stempfle, F.; Ritter, B. S.; Mülhaupt, R.; Mecking, S., Long-chain aliphatic polyesters from plant oils for injection molding, film extrusion and electrospinning. Green Chem. 2014, 16 (4), 2008-2014.

42. Trzaskowski, J.; Quinzler, D.; Bährle, C.; Mecking, S., Aliphatic Long-Chain C20 Polyesters from Olefin Metathesis. Macromol. Rapid Commun. 2011, 32 (17), 1352-1356.

43. Vilela, C.; Silvestre, A. J. D.; Meier, M. A. R., Plant Oil-Based Long-Chain C26 Monomers and Their Polymers. Macromol. Chem. Phys. 2012, 213 (21), 2220-2227.

44. Bouyahyi, M.; Duchateau, R., Metal-Based Catalysts for Controlled Ring-Opening Polymerization of Macrolactones: High Molecular Weight and Well-Defined Copolymer Architectures. Macromolecules 2014, 47, 517-524.

45. Pepels, M. P. F.; Hermsen, I.; Noordzij, G. J.; Duchateau, R., Molecular Structure-Catalytic Activity Relationship in the Ring-Opening Polymerization of (Macro)lactones. Macromolecules 2016, 49 (3), 796806.

46. van der Meulen, I.; Gubbels, E.; Huijser, S.; Sablong, R.; Koning, C. E.; Heise, A.; Duchateau, R., Catalytic Ring-Opening Polymerization of Renewable Macrolactones to High Molecular Weight Polyethylene-like Polymers. Macromolecules 2011, 44 (11), 4301-4305.

47. Guzei, I. A.; Wendt, M., An improved method for the computation of ligand steric effects based on solid angles. Dalton Trans. 2006, (33), 3991-3999.

48. Guzei, I. A. W., M. Program Solid-G, UW-Madison, WI, USA, 2004.

49. Chen, H.-Y.; Lu, W.-Y.; Chen, Y.-J.; Hsu, S. C. N.; Ou, S.-W.; Peng, W.-T.; Jheng, N.-Y.; Lai, Y.C.; Wu, B.-S.; Chung, H.; Chen, Y.; Huang, T.-C., Synthesis, characterization, and catalytic activity of titanium iminophenoxide complexes in relation to the ring-opening polymerization of L-lactide and $\varepsilon$ caprolactone. J. Polym. Sci., Part A: Polym. Chem. 2013, 51 (2), 327-333. 


\section{Table of Contents Graphic and Summary}

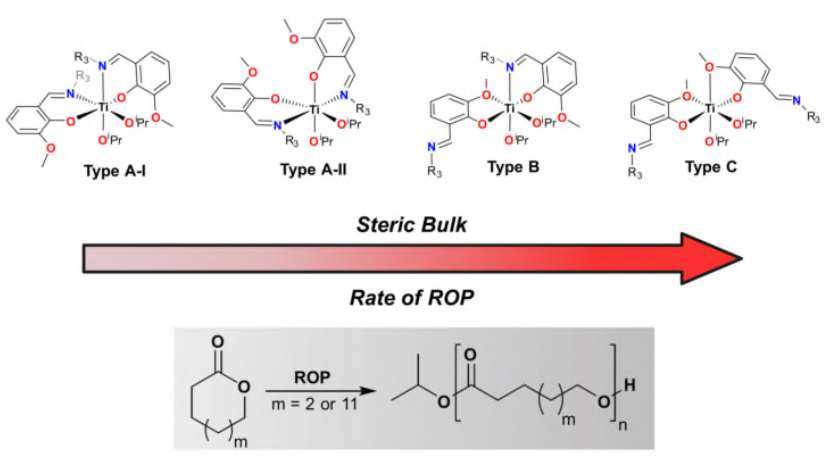

Varying steric bulk of o-vanillin derived bis(phenoxy-imine)Ti(IV) complexes allows access to new coordination isomers, which impacts the rate of ring-opening polymerization of lactones. 